Бондаренко С. А., Вахрушева Е. А.

S. A. Bondarenko, E. A. Vakhrusheva

РАЗРАБОТКА ФИНАНСОВОЙ СТРАТЕГИИ ПРЕДПРИЯТИЯ

\title{
DEVELOPMENT OF FINANCIAL STRATEGY OF ENTERPRISE
}

Бондаренко Светлана Аркадьевна - магистрант кафедры экономики, финансов и бухгалтерского учёта Комсомольского-на-Амуре государственного университета (Россия, Комсомольск-на-Амуре); 681013, Хабаровский край, г. Комсомольск-на-Амуре, пр. Ленина, 27. E-mail: buka0694@mail.ru.

Svetlana A. Bondarenko - graduate student, Department of Economics, Finance and Accounting of Komsomolskon-Amur State University (Russia, Komsomolsk-on-Amur); 681013, Khabarovsk territory, Komsomolsk-on-Amur, 27 Lenin str. E-mail: buka0694@mail.ru.

Вахрушева Елена Анатольевна - доцент кафедры экономики, финансов и бухгалтерского учёта, кандидат экономических наук Комсомольского-на-Амуре государственного университета (Россия, Комсомольск-наАмуре); 681013, Хабаровский край, г. Комсомольск-на-Амуре, пр. Ленина, 27. E-mail: elena_vah@list.ru.

Ms. Elena A. Vakhrusheva - Associate Professor, Department of Economics, Finance and Accounting, Candidate of Economic Sciences, Komsomolsk-on-Amur State University (Russia, Komsomolsk-on-Amur); 681013, Khabarovsk territory, Komsomolsk-on-Amur, 27 Lenin str. E-mail: elena_vah@list.ru.

Аннотация. В данной работе представлены теоретические основы разработки финансовой стратегии предприятия: понятия, направления, виды и цели. Рассматривается принцип концепции стратегического управления.

Summary. This paper presents the theoretical basis for the development of financial strategy of the enterprise: concepts, directions, types and goals. The principle of the concept of strategic management is considered.

Ключевые слова: финансовая стратегия, стратегическое управление, финансовая безопасность, финансовые ресурсы, финансовая деятельность.

Key words: financial strategy, strategic management, financial security, financial resources, financial activities.

УДК 336.02

В современной экономике финансовая стратегия предприятия играет определяющую роль в обеспечении эффективного привлечения и использования его финансовых ресурсов, координации их потоков, что, в конечном счёте, обеспечивает рост рыночной стоимости предприятия и благосостояния его собственников.

Финансовая стратегия является мощным инструментом достижения приоритетных финансовых целей предприятия и его собственников. Степень эффективности реализации финансовой стратегии зависит от правильности её разработки, полноты учёта и оценки факторов, влияющих на предприятие. Это требует раскрытия сущности и содержания финансовой стратегии, её функций, этапов, методов и инструментов, а также факторов, оказывающих воздействие на её формирование.

При разработке финансовой стратегии предприятия большинство менеджеров используют в качестве основного принципа концепцию «стратегическое уравнение», которая отражает политику и финансы предприятия.

Сущность концепции стратегического управления заключается в разграничении следующих видов стратегий развития предприятия:

- корпоративной;

- стратегии бизнес-единиц;

- функциональной. 
Бондаренко С. А., Вахрушева Е. А.

РАЗРАБОТКА ФИНАНСОВОЙ СТРАТЕГИИ ПРЕДПРИЯТИЯ

Модель концепции стратегического управления предприятием представлена на рис. 1 [4].

\begin{tabular}{|l|l|}
\hline Корпоративная стратегия & Миссия предприятия \\
\hline Стратегия бизнес-единиц & $\begin{array}{l}\text { Усиление конкурентных позиций, объединение } \\
\text { стратегических инициатив функцинальных } \\
\text { отделов; меры, связанные с изменениями } \\
\text { в отрасли, и др. }\end{array}$ \\
\hline Функциональные стратегии & $\begin{array}{l}\text { Маркетинговая, производственная, финансовая, } \\
\text { инвестиционная и т. д. }\end{array}$ \\
\hline
\end{tabular}

Рис. 1. Модель концепции стратегического управления предприятием

Первым этапом является разработка корпоративной стратегии, которая определяет основные перспективы и направления деятельности предприятия в целом. Следующим этапом является разработка стратегии бизнес-единиц, которая направлена на повышение конкурентных позиций отдельных видов бизнеса и повышение их рентабельности. Заключительным этапом является разработка функциональных стратегий в зависимости от видов предприятия.

Финансовая стратегия предприятия необходима, так как с помощью финансов можно сбалансировать и скорректировать принятые решения, минимизировав риски деятельности предприятия, не изменив при этом главную цель.

В экономической литературе существует множество определений финансовой стратегии предприятия. Например, отечественные авторы подразумевают под этим термином направления развития предприятия, которые необходимы для достижения поставленных целей в долгосрочной перспективе. По их мнению, реализация финансовой стратегии осуществляется путём мобилизации, эффективного распределения и использования финансовых ресурсов.

Экономист И. П. Геращенко под финансовой стратегией подразумевает генеральный план действий по обеспечению денежными средствами предприятия [3]. Под финансовой стратегией А. К. Вилькомир подразумевает долговременный курс финансовой политики предприятия, рассчитанный на перспективу и предполагающий решение больших задач предприятия [2].

Наиболее полное понятие финансовой стратегии предприятия сформулировано И. А. Бланком, согласно которому - это один из видов функциональной стратегии, обеспечивающей все направления развития финансовой деятельности и финансовых отношений предприятия путём формирования долгосрочных финансовых целей, а также выбора наиболее эффективных путей их достижения. В своих публикациях И. А. Бланк выделяет доминантные направления финансового развития предприятия:

- стратегия формирования финансовых ресурсов (создание потенциальных финансовых ресурсов предприятия, удовлетворяющих потребности, связанные с развитием предприятия);

- инвестиционная стратегия (рациональное использование финансовых ресурсов предприятия, учёт соотношения риска и доходности предприятия, рациональное распределение финансовых ресурсов в зависимости от направлений и форм инвестирования);

- стратегия обеспечения финансовой безопасности предприятия (обеспечение финансовой устойчивости предприятия в процессе стратегического планирования);

- стратегия повышения качества управления финансовой деятельностью предприятия в стратегической перспективе [1].

Таким образом, можно сделать вывод о том, что финансовая стратегия предприятия представляет собой перспективное направление развития его финансовой деятельности и финансовых 
отношений в долгосрочном периоде. Финансовая стратегия предприятия разрабатывается на основе анализа его финансового состояния, результатов хозяйственной деятельности, динамики рынков выпускаемой продукции, оценки потенциальных рисков, сильных и слабых сторон, конкурентных позиций. В результате этого можно определить основные цели реализации финансовой стратегии предприятия, которые представлены на рис. 2 [4].

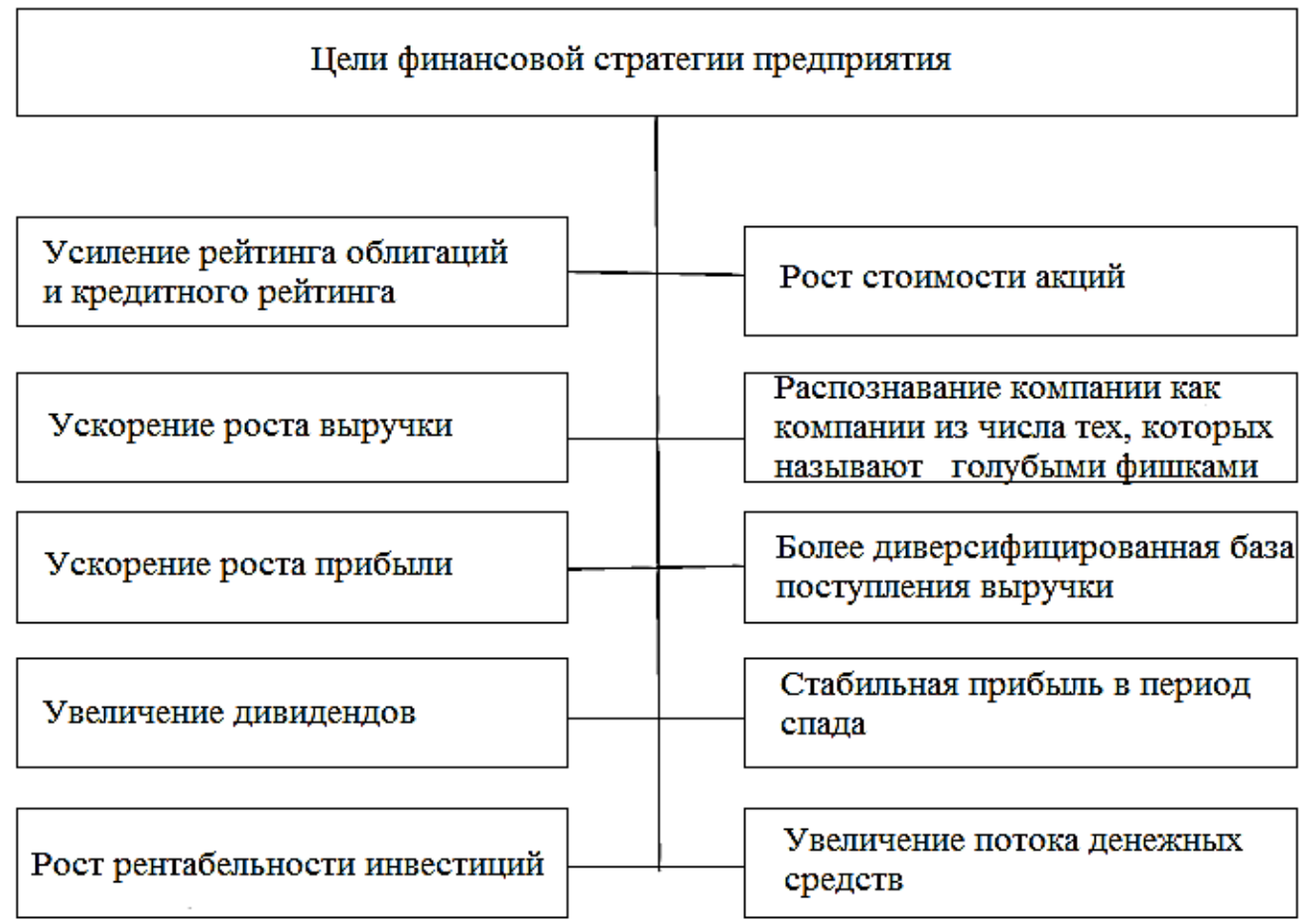

Рис. 2. Цели финансовой стратегии

Сущность финансовой стратегии предприятия заключается в определении приоритетных целей и системы мероприятий по их достижению в области формирования финансовых ресурсов, оптимизации структуры капитала и эффективного использования активов, соответствующих общей концепции развития предприятия и обеспечивающих её реализацию.

В зависимости от времени реализации стратегии различают следующие её виды:

- генеральная финансовая стратегия (разрабатывается сроком на один год и охватывает взаимоотношения с бюджетами всех уровней, образование и использование доходов, потребности в финансовых ресурсах и источниках их формирования);

- оперативная финансовая стратегия (разрабатывается сроком на квартал или месяц и представляет собой распределение и использование финансовых ресурсов);

- стратегия выполнения отдельных стратегических задач (исполнение текущих финансовых обязательств качественно и быстро).

Генеральная финансовая стратегия решает такие проблемы предприятия, как формирование и анализ годовой финансовой отчётности, дивидендная политика, уплата налога на прибыль и т. д.

Реализация оперативной финансовой стратегии представляет собой возможность прогнозирования на планируемый период оборотов по поступлению и расходам денежных средств на предприятии.

Стратегия выполнения отдельных стратегических задач определяется кадровой составляющей предприятия, степенью подготовки и квалификации менеджеров, качеством организационной структуры управления предприятием [5]. 
Бондаренко С. А., Вахрушева Е. А.

Таким образом, мы пришли к выводу о том, что эффективность функционирования, рентабельность деятельности, конкурентоспособность предприятий зависит от грамотного выбора, разработки и реализации финансовой стратегии, которая является составляющей общей корпоративной стратегии предприятия. Финансовая стратегия определяет поведение предприятия на рынке, формирует его рыночную позицию, оперируя источниками финансирования и направлениями использования финансовых ресурсов данного предприятия.

Успех финансовой стратегии предприятия осуществляется при взаимной увязке теории и практики финансовой стратегии, соответствии финансовых стратегий финансовым возможностям предприятия через жёсткую централизацию финансового стратегического руководства и гибкость его методов по мере изменения финансово-экономической ситуации.

\section{ЛИТЕРАТУРА}

1. Бланк, И. А. Финансовая стратегия предприятия: учеб. пособие. / И. А. Бланк. - М.: Эльга, 2013. - 725 с. 2. Вилькомир, А. К. Принципы и методы финансовой стратегии предприятия: учеб. пособие. / А. К. Вилькомир. - М.: Финансовый анализ, 2013. - 89 с.

3. Геращенко, И. П. Финансовая стратегия: учеб. пособие. / И. П. Геращенко. - М.: Книжный дом, 2014. $350 \mathrm{c}$.

4. Давыдова, Л. А. Финансовая стратегия предприятия: учеб. пособие. / Л. А. Давыдова. - М.: Финансы и кредит, 2014. - $153 \mathrm{c}$.

5. Илышева, Н. А. Финансовая стратегия организации. / Н. А. Илышева - М.: Профессиональное издательство, 2015. - 156 с. 